Mrs. Lenthall ; 1048, plaiting; by Mad. Juery, done by hand and very superior; 916, ottoman covers, by Mrs. Sybil Smith; 1040, frame needle work, by Mary Franks; and 906, embroidery on satin, by Jane R. Wray.

Some very creditable specimens of tailors' work are exhibited, among which are noticed, No. 949, a black dress coat, by F. Mahan; 1002, sack coat, by Bennett \& Co.; No. 1030, a bangup, by John Reynolds; and No. 961, boy's clothing, by F. A. Hoyt; No. 1087, a highly finished and well made sack coat, by Leidy \& Peters, was deposited too late for competition, as were also several other good articles.

\title{
Conclusion.
}

And now, in closing their arduous duties for the present year, the Committee would remark, that having conferred on articles, which they deemed the most deserving, the number of fifty-one First Premiums, - on those of the next grade fifty-two Second Premiums,and those of a lesser degree of merit, one hundred and thirteen Third Premiums; and having also noticed as worthy of credit and approbation such other articles as they conceived worthy of such mention; they return their thanks to the depositors and to the public, for the interest manifested in the exhibition. It has been computed that including members of the Institute, depositors, and ladies and minors introduced by them, not less than seventy thousand persons visited the rooms during the eleven days they continued open. This degree of attention and public favor is honorable to the Institute, and will be felt and regarded as a renewed stimulus to exertion in accomplishing the great object of its charter, "the promotion of the mechanic arts."

\section{COMMITTEE ON SCIENCE AND THE ARTS.}

\section{Report on Jos. S. Lovering \& Co.'s Double Refined Sugars.}

The Committee on Science and the Arts corstituted by the Franklin Institute of the State o

Penneylvania, for the promotion of the Meclusuic Arts, to whom was referred for examination specimens of Double Refined Sugars, manufactured in the city of Pbiladelphia, by

Mesers. Jos. 8. Lovnnive \& Co. : Rzpont,

That they have completed an elaborate investigation respecting the purity of the above named sugar, and its economical value, compared with other refined sugars.

The specimen of sugars which was placed in the hands of the committee, was a well formed loaf, weighing about $15 \mathrm{lbs}$., which was taken, indiscriminately, from amongst a large number of others, and deemed by the committee to be a fair a verage specimen of the article as prepared for market; although, perhaps, somewhat inferior to that which was deposited at the last exhibition of the Institute.

The committee do not consider it necessary to detail the numerous experiments which were tried by ultimate analysis, by fermentation, by incineration, by the polarization of light, and by the copper test; and which, in their estimation, conclusively demonstrate the superiority of the above sugars. It is found to approach much nearer to chem- 
ical purity than was to be anticipated from considening the large seale upon which it is manufactured. In reflecting upon this, in connexion with the extreme proneness to alteration, from the action of slight disturbing causes, which sugar exhibits, and the many delicate processes through which it has to pass before it is brought to such a degree of purity, the committe have folt that they could not withhold the expression of their admiration.

The committee, moreover, highly appreciate the enterprize and skill which the Messes. Lovering \& Co. were the first, in this eountry, to exhibit, in applying some of the refined improvements in modern science to a most important and extensive branch of the manufacturing arts.

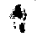

In conclusion, the committee state that, in theiropinion, the Mossrs. Lorering \& Ca are desenving of the highest atrand of the Institute, on account of the perfection to which they have brought the refining of sugar, and the great superiority of their double loaf sugar.

By onder of the Committee,

\section{Philadelphia; June 12, 1845.}

W.M. Hamizion, Actuary.

\section{Report on HuBBELL's Improvement in Fire Arms.}

The Committee on Science and the Arts constituted by the Franklin Institute of the State of

Pennsylvania, for the promotion of the Mechanic Arts, to whom was referred for examination the improvement in Fire Arms, by Wu. W. Hors Brx, Esq., of Philadelphia, Pa. : Rxport,

That they have examined the same, and find it to consist, in the language of the claim in the patent, of a "breech opening and closing on a rod as a centre, \&c.," or, in other words, of a movable breech, which turns upon a joint formed of a screw bolt, which connects the barrel with the stock; a correspondent screw bolt, parallel with that last mentioned, upon the opposite side of the breech and barrel, also serves to connect the barrel with the stock, and aids in support of the recoil ; there is, in addition, a connecting bar under the barrel, which aids in tying it to the stock. The whole forming a cradle, in which the breech lies when in its place for firing, and in which it is held by a spring conveniently placed for that purpose.

The committee are of opinion that the construction admits of rapid - charging and firing, with cartridges, or otherwise, with ball.and buckshot, or small shot, at will. That the movable breech may be safely constructed, that the fastenings or ties by which the barrel and stock are connected are well placed, and that the whole arrangement is not more bulky than seems essential in the construction of fire arms with a movable chamber.

It is proper to add, nevertheless, that the examination of the committee was confined, necessarily, to a visual inspection. 'This arrangement, like every thing else, is liable to inconveniences in use; the committee, as in duty bound, will point ont thoselikely to affect that uader consideration, the most preminent of which is the want of sufficient 